\title{
Experimental transformations of zinc oxide nanoparticles in redox-dynamic freshwater sediments
}

\section{LUCIE STETTEN ${ }^{1}$, FRANK VON DER KAMMER ${ }^{2}$ AND THILO HOFMANN ${ }^{2}$}

${ }^{1}$ Department of Environmental Geosciences, Centre for Microbiology and Environmental Systems Science, University of Vienna

${ }^{2}$ Centre for Microbiology and Environmental Systems Science, University of Vienna

Presenting Author: lucie.stetten@univie.ac.at

The increasing release of $\mathrm{ZnO}$ nanoparticles from anthropogenic sources raises concern regarding their fate in the environment, especially since soils and sediments are found favorable for their accumulation [1]. Whereas studies on unsaturated soils showed that, $\mathrm{ZnO}$ is converted into $\mathrm{Zn}$-rich layered double hydroxides and $\mathrm{Zn}$ adsorbed species, in the presence of sulfides, it is recognized that $\mathrm{ZnO}$ transform into $\mathrm{ZnS}$ phases [2,3]. However, despite formation of $\mathrm{ZnS}$ has been reported in environmental samples [4], the fate of $\mathrm{ZnO}$ nanoparticles in redox-dynamic sediments is still poorly understood. Here, based on laboratory experiments, we investigated the fate of $\mathrm{ZnO}$ nanoparticles in sediments and assessed the geochemical and physicochemical factors controlling $\mathrm{ZnO}$ nanoparticles transformation.

Lacustrine sediments were spiked with $\mathrm{ZnO}$ nanoparticles and incubated under either oxic or anoxic conditions. Using EXAFS spectroscopy at the $\mathrm{Zn} \mathrm{K}$-edge and geochemical analyses, we revealed the rapid dissolution of $\mathrm{ZnO}$ nanoparticles under oxic conditions within a few hours. $\mathrm{Zn}$ released from dissolving $\mathrm{ZnO}$ nanoparticles mainly adsorbs onto phyllosilicate minerals. By contrast, $\mathrm{ZnO}$ nanoparticles dissolution under anoxic conditions is much slower, with $\sim 20 \%$ of $\mathrm{ZnO}$ nanoparticles remaining after 81 days of incubation. Only $40 \%$ of the total $\mathrm{Zn}$ is found in the form of amorphous $\mathrm{ZnS}$, in mixture with $\mathrm{Zn}$ adsorbed species. In contrast, $\mathrm{ZnS}$ is the only observed specie in the control experiments spiked with dissolved $\mathrm{Zn}^{2+}$. While under oxic conditions, the presence of intermediate $\mathrm{Zn}$-organic species suggest that $\mathrm{ZnO}$ nanoparticles dissolution is enhanced by organic compounds, EXAFS spectroscopy combined with geochemical analyses suggest that $\mathrm{ZnO}$ dissolution, the formation of free $\mathrm{Zn}^{2+}$ and the adsorption to sediment particles under anoxic conditions is inhibited by the presence of sulfides.

Altogether, our results bring important information on the stability of $\mathrm{ZnO}$ nanoparticles in redox-dynamic sediments and show that further investigations are needed to better understand the mechanisms controlling $\mathrm{ZnO}$ nanoparticles fate in such environments.

[1] Gottschalk et al. Environmental Pollution 2013, 181, 287300

[2] Voegelin et al. Environmental Science \& Technology 2011, 45, 255-261

[3] Ma et al. Environmental Science \& Technology 2013, 47 (6), 2527-2534 